\title{
Noni (Morinda citrifolia L.) relationship analysis based on morphology character and random amplified polymorphic DNA (RAPD)
}

\author{
R Heryanto $^{1^{*}}$ and T Arlianti ${ }^{1}$ \\ ${ }^{1}$ Indonesian Spice and Medicinal Crops Research Institute, Indonesian Agency for \\ Agricultural Research and Development, Bogor, Indonesia
}

*Corresponding author email: rubiheryanto87@gmail.com

\begin{abstract}
Noni (Morinda citrifolia L.) is a tropical plant with many benefits, one of which is traditional medicine. Moreover, noni can grow in all types of climates. Plant diversity is the main key in plant breeding. The existence of a diverse plant makes it easy for breeders to assemble varieties. This study aims to determine the diversity and relationship of noni germplasm based on morphological characters and RAPD markers. The materials used ten noni accessions at Cimanggu Research Station, Indonesian Spice and Medicinal Crops Research Institute (ISMCRI), Bogor, West Java. The morphological characters observed were leaf length, leaf width, number of pods, fruit diameter, fruit weight, and number of seeds. There were 20 primers used for RAPD. The results showed that morphological characters of leaf shape, fruit shape, and the number of seeds could distinguish noni. Molecular analysis showed that three primers (OPA 9, OPA 17, and OPB 18) could produce polymorphic DNA bands. Based on differences in DNA band patterns, 10 noni accessions were divided into two groups. There is no specific DNA band pattern that distinguishes a total of seeds noni.
\end{abstract}

\section{Introduction}

Noni (Morinda citrifolia) is a medicinal plant that is believed to have originated from Indonesia. This plant is a small tropical evergreen tree native to Southeast Asia (especially Indonesia), Papua New Guinea, and northern Australia [1]. Noni belongs to the Rubiaceae family, where the coffee plant is also the same in the Rubiaceae family. Noni can grow in an extensive range of environments. It can grow in infertile, acidic, and alkaline soils and is at home in very dry to very wet areas; also, it can grow naturally in relatively dry to mesic sites or lowland areas close to shorelines, or as an important forest understory species in low-elevation Pacific island forests and rain forests [2]. This plant has a characteristic when ripe fruit will smell unpleasant.

The noni plant has been used as traditional medicine by the Polynesians. They believe that every part of the plant can be used as medicine. Flowers, leaves, bark, stems, roots, and fruits of noni can be used [3]. The fruits were used as food treatment for and intestinal problems, while the leaves served to treat wound infections, arthritis, swellings, and similar conditions[4]. Besides that, noni is reputed to have antibacterial, antiviral, antifungal, antitumor, antitubercular effect, analgesic activity, immunological activity, mental health and improve high frequency, anti-helminthic, analgesic, hypotensive, anti-inflammatory, and immune-enhancing [5]. The major components have been 
identified in the Noni plant such as scopoletin, octanoic acid, potassium, vitamin C, terpenoids, alkaloids, anthraquinones (such as nordamnacanthal, morindone, rubiadin, and rubiadin-1-methyl ether, anthraquinone glycoside), b-sitosterol, carotene, vitamin A, flavone glycosides, linoleic acid, Alizarin, amino acids, acubin, L-asperuloside, caproic acid, caprylic acid, ursolic acid, rutin, and a putative proxeronine [6].

Nowadays, noni has two recognized varieties of M. citrifolia (M. citrifolia var. citrifolia and $M$. citrifolia var. bracteata) and one cultivar (M. citrifolia cultivar Potteri) where the most commonly found variety is $M$. citrifolia var. citrifolia, with the greatest health and economic importance [7]. Indonesian Spices and Medicinal Crops Research Institute is a research institute under the Ministry of Agriculture of Indonesia that collects noni conserved in research installation. This collection is one of the activities in preserving these plants.

Knowing the genetic relationship between plants is one of the breeding activities for creating new varieties. Knowledge about genetic relationships will be useful to avoid the chance of using genetically similar genotypes/landraces. It will also be supportive in future breeding programs to select genetically diverse parents [8]. Plant genetic kinship relationships can be evaluated through pedigree, simultaneous analysis of quantitative traits, and molecular markers analysis [9]. Plants' morphological properties can be observed by looking at the outside appearance, but the environment can influence these morphological characteristics. Meanwhile, the kinship analysis's molecular marker is often used is the Random Amplified Polymorphic DNA (RAPD). The marker of RAPD inheritance is dominant so that the homozygous phenotype is indistinguishable from the heterozygous phenotype and is less sensitive. However, this drawback can be overcome by using more primers [10]. This study aims to determine the relationship of noni based on morphological characters and molecular markers. Also, this research can be used in future breeding.

\section{Material and method}

\subsection{Plant material}

The material used in this study is 10 noni accessions at Cimanggu Research Station, Indonesian Spice and Medicinal Crops Research Institute (ISMCRI), Bogor, West Java. The research was conducted from January to August 2020 at the Cimanggu Research Station, Indonesian Spice, and Medicinal Research Institute, Bogor, West Java, Indonesia.

\subsection{Observation of morphological traits}

The study was conducted with a descriptive method which observed the morphological character of plants. Morphological characters of plants observed are quantitative data. The quantitative plant morphological characters observed were leaf length, leaf width, number of pods, fruit diameter, fruit weight, and number of seeds.

\subsection{Analysis of morphological data}

The measurement of correlation was based on mean values using $\mathrm{R}$ software. The correlation for evaluates the relationships among the different variables in the experiment. The following formula calculates the coefficient of diversity:

$$
\begin{gathered}
\boldsymbol{C V}=\frac{\boldsymbol{S}}{\overline{\boldsymbol{x}}} \\
S=\frac{\sum_{i=1}^{n}\left(x_{i}-\bar{x}\right)^{2}}{n-1}
\end{gathered}
$$

Where: $\mathrm{S}=$ Standard Deviation

$\bar{x}=$ means of observation value

$\mathrm{x}_{\mathrm{i}}=$ observation $-\mathrm{i}(\mathrm{i}=1,2,3,4,5)$ 
$\mathrm{n}=$ total of sample observation

The value coefficient variance (CV) is used to estimate the level of diversity of the observed accessions characters, namely the $\mathrm{CV}$ value of $0-25 \%$ indicates low diversity, while the high diversity level is if the $\mathrm{CV}$ value is $>25 \%$. The means of each morphological trait were used for cluster analysis. Euclidean distance was used as the similarity coefficient for cluster analysis with the Unweighted Pair Group Arithmetic Means method (UPGMA) using R software. Principal component analysis (PCA) was performed on morphological data to certain that the dendrogram is a good representation of the data

\subsection{DNA Extraction and RAPD procedure}

Young leaves samples from each noni accession were extracted using the modified CTAB method [10]. DNA concentration was quantified by using the Nano Drop Spectrophotometer 2000 (Thermo scientific, Germany) and qualified using agarose gel electrophoresis (Bio-Rad, USA).

The PCR reaction was carried out with a total volume of $12 \mu$ l containing Taq polymerase $(6.25$ $\mu 1)$, primer $(1 \mu \mathrm{l})$, DNA $(5 \mu \mathrm{l})$, and water $(0.25)$. A total of about 20 primers from Operon Technology were used (Table 1). DNA amplification was performed in an RT-PCR rotor gene Q programmed to 1 cycle of $5 \mathrm{~min}$ at $95^{\circ} \mathrm{C}$ followed by 35 cycles $95^{\circ} \mathrm{C}$ for $1 \mathrm{~min}, 35^{\circ} \mathrm{C}$ for $1 \mathrm{~min}, 75^{\circ} \mathrm{C}$ for 2 min ending with 1 cycle of $10 \mathrm{~min}$ at $72^{\circ} \mathrm{C}$ (final extension). The PCR amplification results were visualized on $1.5 \%$ agarose gel in a TBE buffer (Tris-EDTA) electrophoresis using Mupid Mini Cell for 45 minutes at 80 volts. The results of the electrophoresis were photographed using UVITEC Cambridge. As the standard for the DNA size, a $100 \mathrm{bp}$ DNA ladder (Promega) was used to determine the size of the DNA amplified band

Table 1. RAPD primer that used in the research

\begin{tabular}{cccccccc}
\hline No & Primer & No & Primer & No & Primer & No & Primer \\
\hline 1 & OPA9 & 6 & OPO 20 & 11 & OPK 12 & 16 & OPC 2 \\
2 & OPB 18 & 7 & OPN 10 & 12 & OPO 2 & 17 & OPA 17 \\
3 & OPN 13 & 8 & OPB 13 & 13 & OPO 15 & 18 & OPC 4 \\
4 & OPN 18 & 9 & OPB 16 & 14 & OPB 8 & 19 & OPA 2 \\
5 & OPN 3 & 10 & OPB 7 & 15 & OPA 4 & 20 & OPA 12 \\
\hline
\end{tabular}

\subsection{Analysis data of molecular marker}

RAPD is the dominant marker, so each RAPD band is considered a single biallelic locus [11]. The results of the visualization of DNA strands were scored based on the DNA fragment bands that were implicated with the classification "1" indicating bands, and " 0 " showing no bands. The scoring results will be analyzed using $\mathrm{R}$ software. Cluster analysis to determine genetic distance by Euclidean distance with Unweighted Pair Group Arithmetic Means method (UPGMA) using R software.

\section{3. Result and Discussion}

\subsection{Correlation among morphological trait}

The analysis results showed a significant level of phenotypic variation between 10 accessions of noni in morphological characters (Table 2). The noni's highest mean value for the number of seeds with value 205 , fruit weight with value 102 , fruit diameter with value 86.4 , and the number of pods with value 86.4. The highest coefficient of variation (CV) is the characteristics of the number of seeds and fruit weight. The value of the coefficient variety of each character is $72.20 \%$ and $34.22 \%$. The enormous variance is the number of seeds with a variance value of 21867 and fruit weight $\mathrm{s}$ with a variance value of 1217 . The CV value is used to estimate the level of observed character diversity if 
the $\mathrm{CV}$ value of $0-25 \%$ indicates low diversity, while if the $\mathrm{CV}$ value is $>25 \%$ shows high diversity [9]. The high diversity of these characters will provide opportunities for superior accession through selection. A high variance value indicates that the observed data fluctuates.

Table 2. Variation in morphological traits of 10 noni accessions

\begin{tabular}{lcccccc}
\hline \multicolumn{1}{c}{ Traits } & Mean & Minimum & Maximum & SD & CV (\%) & Variance \\
\hline Leaf Length & 26.8 & 24.4 & 31 & 2.17 & 8.10 & 4.7 \\
Leaf Width & 13.9 & 12.3 & 15.6 & 1.03 & 7.41 & 1.07 \\
Fruit Weight & 102 & 56.5 & 154 & 34.9 & 34.22 & 1217 \\
Fruit Diameter & 86.4 & 59.7 & 109 & 14.9 & 17.25 & 222 \\
Number of Pods & 86.4 & 59.7 & 109 & 14.9 & 17.25 & 222 \\
Number of Seeds & 205 & 2.5 & 371 & 148 & 72.20 & 21876 \\
\hline
\end{tabular}

* CV: Coefficient of Variation

The result of correlation coefficients between morphological traits given in Table 3. The character between fruit morphology has a positive and significant correlation. The morphological characters' leaf length gave a positive correlation to all observed characters except the number of seeds. Likewise, leaf width provides a positive correlation on leaf length, number of pods, and fruit diameter. It was the leaf length and the leaf width, which negatively correlated to the number of seeds and the fruit weight with the leaf width. The positive correlation occurs if the morphological traits interact with each other. The negative correlation is shown no interaction traits with each other. The correlation between characters will make it easier for breeders to determine the plant's important characters [12]. Correlated traits can be used as selection criteria in selecting plants.

Table 3.Correlation coefficients among morphological traits.

\begin{tabular}{lcccccc}
\hline & $\begin{array}{c}\text { Leaf } \\
\text { Length }\end{array}$ & $\begin{array}{c}\text { Leaf } \\
\text { Width }\end{array}$ & $\begin{array}{c}\text { Number of } \\
\text { Pods }\end{array}$ & $\begin{array}{c}\text { Fruit } \\
\text { Diameter }\end{array}$ & $\begin{array}{c}\text { Fruit } \\
\text { Weight }\end{array}$ & $\begin{array}{c}\text { Number } \\
\text { of Seeds }\end{array}$ \\
\hline Leaf Length & - & & & & & \\
Leaf Width & 0.378 & - & & & & \\
Number of Pods & 0.025 & 0.113 & - & & & \\
Fruit Diameter & 0.025 & 0.113 & $1^{* * *}$ & - & - & \\
Fruit Weight & 0.255 & -0.068 & $0.793^{* *}$ & $0.793^{* *}$ & - \\
Number of Seeds & -0.028 & -0.188 & 0.466 & 0.466 & $0.757^{*}$ & - \\
\hline Note. ${ }^{*} \mathrm{p}<.05, * * \mathrm{p}<.01, * * \mathrm{p}<.001^{*}$ & & & & & &
\end{tabular}

\subsection{RAPD fingerprint}

Noni accession was analyzed using 20 RAPD primers, out of 8 produced polymorphic and reproducible fragments. These primers produce a total of 28 amplified DNA fragments in all samples, with an average of 3 amplified DNA per accession. The number of amplified DNA ranged from 2-6, with an average of 3 amplified DNA per primer. Almost all the DNA fragments were polymorphic, which 21 bands polymorphic or equivalent with $78 \%$ of the total band (Table 4). The number of polymorphic bands varied from $1-5$ with an average of 2.6 per primer. The maximum number of polymorphic bands was 5 and amplified with OPB 18 . The most informative primer was OPB 18, OPA 9, OPA 17, and OPA 18. Bordalloet al. (2017)[13] used 20 RAPD primers on 36 plants of 13 accessions M.citrifolia and found OPA4 as the most polymorphic primer with 11 polymorphic bands. The high polymorphism rate (more than $50 \%$ ) was by other research that used RAPD marker on Morinda spp ([14]; [15]; [16]; [17]). The high number of polymorphic bands might be since the samples were obtained from several different places before planted in ISCMRI. Furthermore, although noni has been described as a preferentially self-pollinating plant [18], it also has pistillate florets [19], suggesting the possibility of cross-pollination, which might be associated with the high number of polymorphic bands. There was no significant difference in DNA band pattern found between the 
seedling and non-seeding accession (no 3 and 8) in all RAPD primer used. Accession number 3 tends to have a similar band with accession 2,4,5; meanwhile the accession number 8 had a similar band with numbers 7 and 9 (Figure 1). The result confirms that the RAPD technique is considered efficient for determining the genetic variability of noni germplasm. Analyzed 10 germplasm of sweet potato using three DNA markers and found the polymorphic rate of RAPD was the same with AFLP and higher than SAMPL [20].

Table 4. Polymorphism detected with 8 RAPD primer in 10 noni germplasm accessions.

\begin{tabular}{lccccc}
\hline \multirow{2}{*}{ Primer } & \multirow{2}{*}{ Sequence (5'-3') } & \multirow{2}{*}{ Total no of bands } & \multicolumn{2}{c}{ Polymorphic } & \multirow{2}{*}{ Amplicon band size } \\
\cline { 4 - 5 } & & 6 & 5 & 83 & $300-1000$ \\
\hline OPB18 & CCACAGCAGT & 4 & 3 & 75 & $500-1000$ \\
OPA 9 & GGGTAACGCC & 2 & 2 & 100 & $100-1000$ \\
OPA 17 & CATTGGGGAG & 4 & 4 & 100 & $400-500$ \\
OPN 3 & GGTACTCCCC & 3 & 3 & 100 & $300-500$ \\
OPN 13 & AGCGTCACTC & 3 & 2 & 67 & $300-500$ \\
OPA 18 & GGTGAGGTCA & 2 & 1 & 50 & $100-500$ \\
OPN 10 & ACAACTGGGG & 2 & 1 & 50 & $100-500$ \\
OPN 16 & AAGCGACCTG & 26 & 21 & 78 & \\
\hline
\end{tabular}

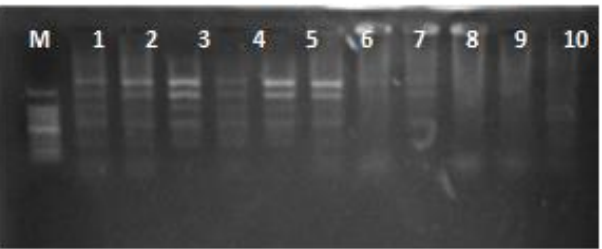

OPB 18

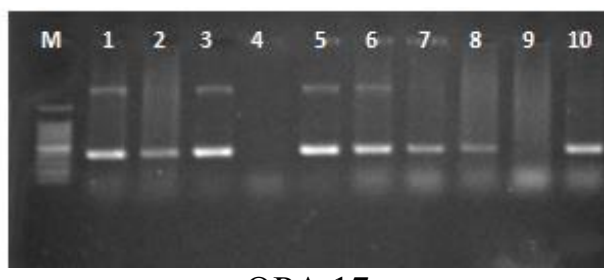

OPA 17

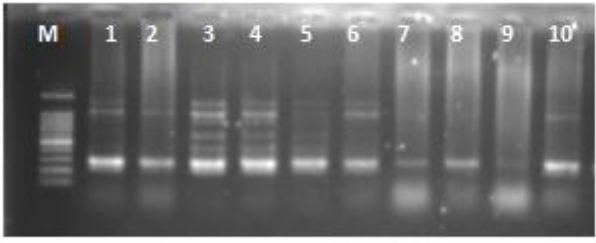

OPA 9

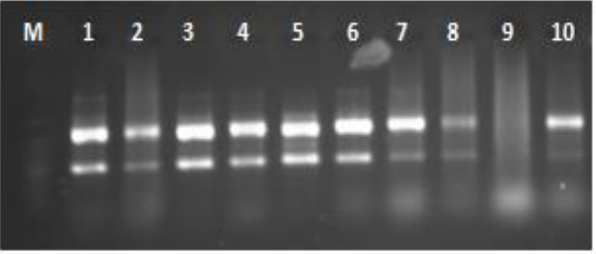

OPA 18

Figure 1. RAPD pattern profile of ten noni accessions described by different RAPD primers $\mathrm{M}=100 \mathrm{bp}$ DNA marker, 1-10 = noni germplasm.

\subsection{Cluster analysis}

Cluster analysis was carried out to determine the closeness between plants. The result of cluster analysis is shown in Figure 2. Figure 2a shows a dendrogram made based on the morphological characters of the fruit. This is done because the correlation results show correlates with fruit morphology traits. Meanwhile, Figure $2 b$ of the dendrogram was made based on the RAPD primer. Based on the dendrogram results based on morphology and primer, 10 noni accessions were divided 
into 2 major groups: group $1(1,3$, and 8$)$ and group $2(2,4,5,6,7,910)$. The small values of the Euclidean distance coefficient between samples show the diversity is low. Based on the dendrogram of accessions 1 with 8 , and 9 with 10 , morphologically and DNA, it shows a close genetic distance. This proves that the accessions are not different morphologically and DNA. Accessions of noni 1 and 8 have little seeds or seedless. Also, 1 or 8 noni accessions can be selected as parents because it has little seeds or seedless.

A

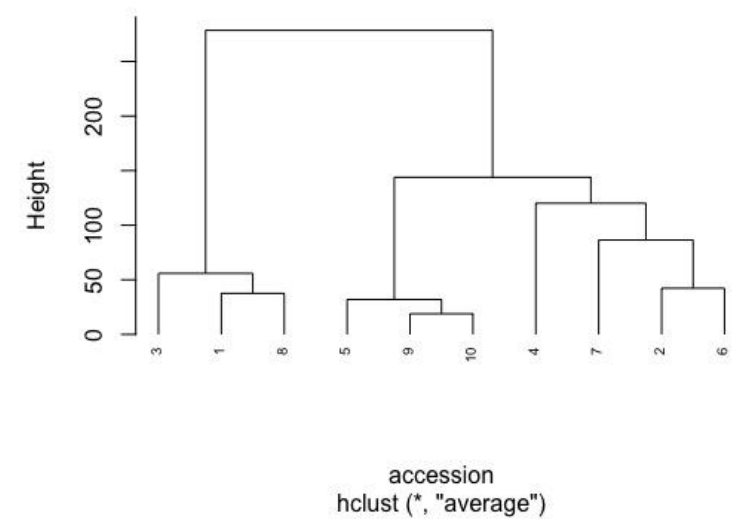

$\mathrm{B}$

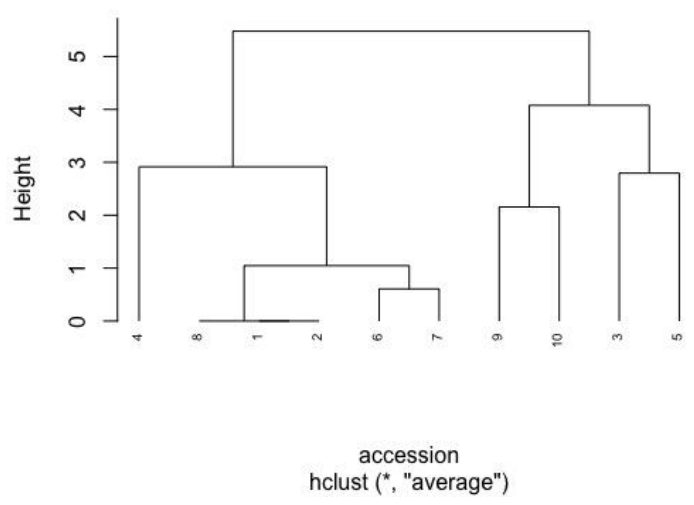

Figure 2. Dendrogram for 10 noni accessions generated by UPGMA clustering using elucidation coefficient of similarity on morphological (a) and RAPD (b) data.

\section{Conclusion}

The diversity of noni accessions is shown in the characters number of seeds and fruit weight with the coefficient of variation values of more than $25 \%$. Based on the cluster analysis, ten noni accessions were divided into 2 groups: group $1(1,3$, and 8) and Group $2(2,4,5,6,7,9$, and 10). Noni accessions 1 and 8 can be select as parents because they have few fruit seeds or seedless.

\section{References}

[1] Macpherson H, Daniells J, Wedding B and Davis C 2007 The Potential for a New Value Adding Industry for Noni Tropical Fruit Producers

[2] Nelson S C 2003 Morinda citrifolia (Permanent Agriculture Resources (PAR), P.O. Box 428, Holualoa, HI 96725 USA)

[3] de Paiva Pinheiro S K, Teófilo F B S, Lima A K M, Cordoba B V, Miguel T B A R and de Castro Miguel E 2019 Ontogenesis and Secretion Mechanism of Morinda citrifolia L. (Rubiaceae) Colleters South African Journal of Botany 121 26-33

[4] Bussmann R W, Hennig L, Giannis A, Ortwein J, Kutchan T M and Feng X 2013 Anthraquinone content in noni (Morinda citrifolia L.) Evidence-based Complementary and Alternative Medicine 2013 20-2

[5] Mownika S, Ramya E K and Sharmila S 2020 Anatomical and Histochemical Characteristics of Morinda citrifolia L. (Rubiaceae) International Journal of Pharmaceutical Sciences and Research 11 669-77

[6] Dar B N and Wani S H 2009 Noni (Morinda Citrifolia L.) -A Hope in a Bottle New Biology: Current Developments/Frontiers in Life Sciences pp 338-53

[7] Abou Assi R, Darwis Y, Abdulbaqi I M, Khan A A, Vuanghao L and Laghari M H 2017 Morinda citrifolia (Noni): A comprehensive review on its industrial uses, pharmacological activities, and clinical trials Arabian Journal of Chemistry 10 691-707

[8] Phadnis S and Peter A 2017 Morphological Studies and Genetic Diversity Analysis of Cardamom ( Elettaria cardamomum Maton .) Genotypes and Hedychium coronarium Using 
RAPD Markers Trends in Biosciences 27 5737-45

[9] Rahadi V P, Khomaeni H S, Chaidir L and Martono B 2016 Genetic Diversity and Relationships of Tea Germplasm Collection Based on Leaf Morphology Character and Yield Components Jurnal Tanaman Industri dan Penyegar 3 103-8

[10] Murray M G and Thompson W F 1980 Rapid isolation of high molecular weight plant DNA Nucleic Acids Research 8 4321-6

[11] Williams J A, Scott I M, Atkin A L, Brook W J, Russell M A and Bell J B 1990 Genetic and molecular analysis of $\operatorname{vg}(\mathrm{U})$ and $\operatorname{vg}(\mathrm{W})$ : Two dominant vg alleles associated with gene fusions in Drosophila Genetics 4 833-44

[12] Sohrabi M, Rafii M Y, Hanafi M M, Siti Nor Akmar A and Latif M A 2012 Genetic diversity of upland rice germplasm in malaysia based on quantitative traits The Scientific World Journal 2012

[13] Bordallo P N N, Monteiro A M R M R, Sousa J A A and Aragão F A S A S 2017 Molecular marker-based genetic diversity analysis of scantly studied Brazilian accessions of a medicinal plant, Morinda citrifolia L. (noni) Genetics and Molecular Research 16 1-7

[14] Singh D R, Srivastava A K, Srivastava A and Srivastava R C 2011 Genetic diversity among three Morinda species using RAPD and ISSR markers Indian Journal of Biotechnology 10285 93

[15] Singh S, Minj D and Kumari C 2012 Diversity of Morinda citrifolia L. in Andaman and Nicobar Islands (India) assessed through morphological and DNA markers African Journal of Biotechnology 11 15214-15225-15225

[16] Arya L, Ramya K N, Kak A, Pandey C D, Verma M and Gupta V 2013 Genetic diversity analysis in Morinda tomentosa collected from Gujarat using RAPD markers Indian Journal of Horticulture 4 580-3

[17] Patel M N, Parmer L D, Parihar A, Singh A K and Sheikh W A 2014 A high-throughput dna extraction protocol and its utilization in molecular characterization of noni (Morinda citrifolia 1.) genotypes Current Trends in Biotechnology and Pharmacy 8 166-74

[18] Nelson S C 2003 Noni Cultivation and Production in Hawai ' i Proceedings of the 2002 Hawai ' $i$ Noni Conference pp 33-50

[19] Waki J, Okpul T and Komolong M K 2008 Assessing The Extent of Diversity among Noni (Morinda citrifolia L.) Genotypes of Morobe Province, Papua New Guinea The South Pacific Journal of Natural and Applied Sciences 26 11-24

[20] Mohamed A A, Far M M M El and Saad M E 2016 Fingerprinting of Sweet Potato Germplasm Using AFLP, RAPD, and SAMPL Analysis Egyptian Journal of Genetics and Cytology 45383 401 